\title{
(2)
}

Santiago Fernández Díez-Picazo*

\section{RELACIÓN ENTRE LAS VARIACIONES DE GASTO PÚBLICO Y PIB}

El objetivo de este estudio es presentar los resultados de un análisis sobre datos de crecimiento y gasto público (fuente: FMI) de 128 países en los últimos 20 años. Se concluye que la probabilidad $(0,80)$ de que un descenso del gasto vaya acompañada de un ascenso del PIB es solo algo menor que la probabilidad $(0,91)$ de que un aumento del gasto vaya acompañada de un crecimiento del PIB. Se dividen los países en varios grupos según las variaciones del PIB y del gasto vayan en la misma dirección o en direcciones opuestas. Se intenta también poner unos límites numéricos a estos comportamientos, y se analiza si el mejor predictor es el mismo país, o el grupo al que pertenece.

Palabras clave: reducción gasto público, aumento gasto público, aumento del PIB, reducción del PIB. Clasificación JEL: E23, E62, H50.

\section{Introducción}

De acuerdo con Mankiw (1977) si representamos el PIB por medio del símbolo $\mathrm{Y}$, entonces

$$
Y=C+I+G+N X
$$

Siendo $C$ el consumo, I la inversión, $G$ las compras del Estado y $N X$ las exportaciones netas.

Citando la teoría general del empleo, el interés y el dinero, de Keynes, Bradford (1995) recuerda que la primera de las tres soluciones -que hoy día se consideran eficaces contra las recesiones- es «políticas fiscales expansionistas y que los Gobiernos sustituyan a la inversión privada cuando esta es débil».

En marzo de 2015, descargué del FMI (2015) datos de 92 países en los últimos 20 años para

* Titulado Superior de los Organismos Autónomos del Ministerio de Industria, Turismo y Comercio.

Versión de marzo de 2016. calibrar por dónde se movía el multiplicador keynesiano del gasto público. Quería contestar a esta pregunta: si el gasto público se reduce $X$ ¿cuánto se reducirá el PIB? ¿0,7X? ¿1,2X? Mi sorpresa fue que, en la mayoría de los casos, una reducción del gasto público en un año iba acompañada de un aumento del PIB ese mismo año. Al ver, meses después, que Krugman (2015) se hacía eco del fenómeno, aunque para un conjunto de países más limitado (mayormente europeos), me ha parecido interesante realizar un análisis detallado.

Los editores me han proporcionado la excelente referencia de Lacalle (2016) que les agradezco efusivamente, donde se proporcionan numerosos enlaces y se menciona como básico un estudio de Mendoza, Ilzetki y Végh donde se analizaron 44 países hasta 2007. El presente artículo analiza 128 países en un período más reciente. Las opiniones y conclusiones contenidas en este artículo son exclusivamente de $\triangleright$ 
su autor. No deben considerarse las de ninguna institución ni organismo.

\section{Datos manejados}

Se han obtenido de la base de datos del boletín Perspectivas Económicas Mundiales (World Economic Outlook, WEO) del FMI. Los datos, descargados en febrero de 2016, abarcan desde 1980 a 2020 (obviamente los datos de 2016 a 2020 son estimaciones. También lo son muchos de 2015 y 2014). Solamente se va a trabajar con los datos de 1995 a 2015 (veintiún años, pero veinte intervalos año-año), porque se considera que la economía mundial ha cambiado sustancialmente desde 1980 con la digitalización y la globalización. Se toman los datos de PIB real a precios constantes, variaciones del PIB real (Gross Domestic Product, constant prices, year-on-year percentage change), porcentaje del gasto público respecto al PIB (General government total expenditure), porcentaje del PIB que supone la deuda bruta ${ }^{1}$ (General government gross debt) y porcentaje del PIB que suponen los ingresos del Estado (General government revenue). Se seleccionan los países donde figuren todos estos datos para el período 1995-2015, con la adición de Estados Unidos. Extrañamente no figuran en el WEO datos de gasto, ingreso público y deuda de EEUU entre 1980 y 2000. Para no eliminar de este análisis a la primera economía mundial, estos datos se han estimado (solo para el corto período 1995-2000) con las series de la Oficina Presupuestaria de la Casa Blanca (https://www. whitehouse.gov/omb/budget), que arrancan de 1930.

Se ha estimado el dato de gasto público de Brasil de 1995, que es el único que falta, con

\footnotetext{
${ }^{1}$ La deuda bruta (gross debt), de la que en español suele hablarse simplemente como «deuda», facilita la mejor medida de la solvencia de un Estado a largo plazo. La deuda neta (que solo incluye los títulos de deuda en manos de inversores) es, en cambio, más relevante si se quiere estudiar cómo se comportan los mercados a corto plazo.
}

los de 1996 y 1997. También se han estimado los datos de gasto público de 1995 a 1997 de Bielorrusia, obviamente erróneos en el WEO (el gasto público pasa de un 0,558 por 100 del PIB en 1997 a un 10,925 por 100 en 1998).

Por falta de datos de gasto público sí se han eliminado países como Israel, Rusia, Sudáfrica, Siria, Turquía y Uruguay. En total se analizan 128 países.

\section{Variación del gasto público}

Como se ha dicho, se representarán las compras del Estado mediante G. El gasto público es mucho más (incluye también los salarios de los empleados públicos, subvenciones, funcionamiento del aparato estatal, etcétera) y se representará por la letra $S$.

Tomaremos la variación de $S$,

$$
\Delta S=100 *\left(S_{n+1}-S_{n}\right) / S_{n}
$$

$S_{n}$ se calcula a partir del PIB real en moneda nacional aplicándole el porcentaje del gasto público respecto al PIB. $\Delta S$ es un porcentaje, pero no respecto al PIB, sino respecto al gasto público del primer año del bienio para el que se calcula la variación.

En total, para los 128 países analizados y los 20 intervalos de variaciones del PIB, se halla que aumenta en 2.242 ocasiones y disminuye en 318. En ningún caso es exactamente igual a 0 . Por tanto, la probabilidad de que aumente el PIB es 0,88.

De la misma forma se halla que el gasto público aumenta en 1.851 ocasiones y disminuye en 709. La variación tampoco es nunca exactamente igual a 0 . En consecuencia, la probabilidad de que aumente el gasto público es 0,72 .

Si estos dos sucesos fueran variables totalmente independientes, la probabilidad de que ocurran a la vez sería 0,63 , el producto de sus probabilidades individuales. 
En la muestra analizada la probabilidad aparente de que una subida del gasto público de un año $n$ a un año $n+1$ vaya acompañada de un incremento del PIB en el año $n+1$ parecería muy cercana a esa cifra. Ocurre en 1.679 ocasiones de las 2.560 analizadas, por lo que podría pensarse que se calcularía:

$$
1.679 / 2.560=0,66
$$

Pero este cálculo no es correcto: no hay que dividir por el número total de variaciones analizadas, sino solamente del número de veces que el gasto público aumentó, esto es, 1.851. Con este cálculo la probabilidad sube considerablemente, a 0,91.

Eso sí, la probabilidad de que un descenso del gasto vaya acompañada de un ascenso del PIB es 0,80 , solo una décima inferior: 568 casos en que el PIB sube y el gasto baja divididos por 709 casos en que el gasto baja.

¿Cómo es esto posible? Si la probabilidad de que el gasto suba y el PIB crezca es 0,91 ¿la probabilidad de que el gasto baje y el PIB crezca no debería ser $1-0,91=0,09$ ?

Pues no. Lo contrario de que el gasto suba y el PIB crezca no es que el gasto baje y el PIB crezca, sino que el gasto suba y el PIB decrezca. Que, efectivamente, es la cifra 172 del Cuadro 1 dividida por las 1.851 veces que el gasto sube, esto es, 0,09.

La distribución por países es muy desigual. Para evidenciarla muestro en el Cuadro 1 los cuatro casos que pueden ocurrir.

Los países donde, en el período analizado, más veces el aumento del gasto público ha ido acompañado de un aumento del PIB (caso 1)

\begin{tabular}{|c|c|c|c|}
\hline \multicolumn{4}{|c|}{$\begin{array}{c}\text { CUADRO } 1 \\
\text { CASOS POSIBLES }\end{array}$} \\
\hline Caso & $\begin{array}{l}\text { Número } \\
\text { que lo } \\
\text { describe }\end{array}$ & $\begin{array}{c}\text { Veces } \\
\text { que } \\
\text { ocurrió }\end{array}$ & Probabilidad \\
\hline$\Delta Y>0, \Delta S>0 \ldots \ldots$ & 1 & 1.679 & 0,66 \\
\hline$\Delta Y>0, \Delta S<0 \ldots \ldots$ & 2 & 568 & 0,22 \\
\hline$\Delta Y<0, \Delta S>0 \ldots \ldots$ & 3 & 172 & 0,07 \\
\hline$\Delta Y<0, \Delta S<0 \ldots \ldots$ & 4 & 141 & 0,06 \\
\hline \multicolumn{4}{|c|}{ Fuente: elaboración propia. } \\
\hline
\end{tabular}

son emergentes de rápido crecimiento, como China, Panamá, Australia e India. Sorprenden temente, también está Francia, país al que últimamente se acusa de estancado y de gasto público excesivo.

\begin{tabular}{|c|c|c|c|c|}
\hline \multicolumn{5}{|c|}{$\begin{array}{c}\text { CUADRO } 2 \\
\text { CAMPEONES DEL CASO } 1\end{array}$} \\
\hline País & 1 & 2 & 3 & 4 \\
\hline Australia ..................................... & 20 & 0 & 0 & 0 \\
\hline 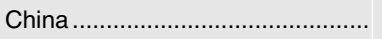 & 20 & 0 & 0 & 0 \\
\hline 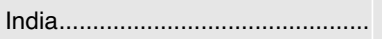 & 20 & 0 & 0 & 0 \\
\hline Panamá .................. & 20 & 0 & 0 & 0 \\
\hline Francia .............................. & 19 & 0 & 1 & 0 \\
\hline 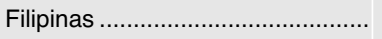 & 18 & 1 & 0 & 1 \\
\hline 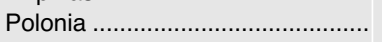 & 18 & 2 & 0 & 0 \\
\hline 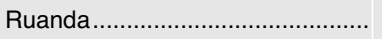 & 18 & 2 & 0 & 0 \\
\hline 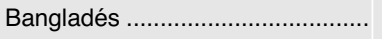 & 17 & 3 & 0 & 0 \\
\hline Costa Rica .................................... & 17 & 2 & 1 & 0 \\
\hline 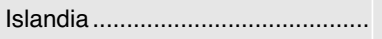 & 17 & 1 & 0 & 2 \\
\hline 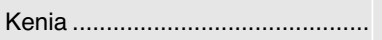 & 17 & 3 & 0 & 0 \\
\hline Corea del Sur .................................. & 17 & 2 & 1 & 0 \\
\hline 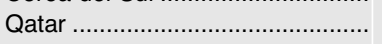 & 17 & 3 & 0 & 0 \\
\hline
\end{tabular}

Los países donde más veces se ha dado que el PIB aumentara aunque el gasto público disminuyera (caso 2) son, por un lado, insulares (Samoa, Cabo Verde, Comores) y por otro, conocidos exportadores de petróleo (Emiratos Árabes Unidos, Noruega, Brunei, Irán).

\begin{tabular}{|c|c|c|c|c|}
\hline \multicolumn{5}{|c|}{$\begin{array}{c}\text { CUADRO } 3 \\
\text { CAMPEONES DEL CASO } 2\end{array}$} \\
\hline País & 1 & 2 & 3 & 4 \\
\hline 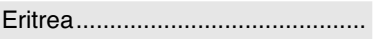 & 6 & 10 & 0 & 4 \\
\hline Samoa & 6 & 10 & 3 & 1 \\
\hline 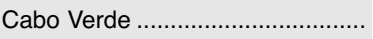 & 10 & 9 & 1 & 0 \\
\hline Italia & 6 & 9 & 3 & 2 \\
\hline Líbano & 10 & 9 & 1 & 0 \\
\hline Brunei & 5 & 8 & 5 & 2 \\
\hline 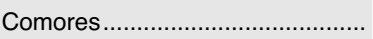 & 10 & 8 & 0 & 2 \\
\hline Irán & 10 & 8 & 1 & 1 \\
\hline 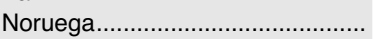 & 11 & 8 & 1 & 0 \\
\hline Emiratos Árabes Unidos ............... & 11 & 8 & 1 & 0 \\
\hline
\end{tabular}

Los países donde más veces se ha dado que el PIB bajara aunque el gasto público creciera (caso 3 ) son los que se reflejan en el Cuadro 4, en la página siguiente.

La lista de campeones del grupo 3 comparte un elemento con la del grupo 4: Brunei. Otros tres integrantes son Japón (en estancamiento $\triangleright$ 


\begin{tabular}{|c|c|c|c|c|}
\hline \multicolumn{5}{|c|}{$\begin{array}{c}\text { CUADRO } 4 \\
\text { CAMPEONES DEL CASO } 3\end{array}$} \\
\hline País & 1 & 2 & 3 & 4 \\
\hline 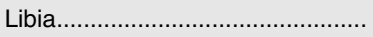 & 8 & 3 & 6 & 3 \\
\hline Santa Lucía & 10 & 3 & 6 & 1 \\
\hline 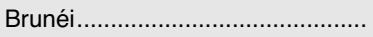 & 5 & 8 & 5 & 2 \\
\hline Croacia............... & 12 & 1 & 4 & 3 \\
\hline 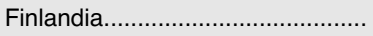 & 14 & 2 & 4 & 0 \\
\hline Japón & 8 & 6 & 4 & 2 \\
\hline Kirguistán & 11 & 5 & 4 & 0 \\
\hline 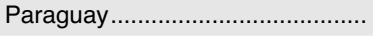 & 10 & 4 & 4 & 2 \\
\hline
\end{tabular}

secular), Libia (en guerra civil) y Finlandia (con una prolongada recesión por la pérdida simultánea de sus mercados de teléfonos móviles y de papel).

Por último, los países donde más veces se ha dado que el PIB bajara y que el gasto público descendiera también (caso 4) son los recogidos en el Cuadro 5.

\begin{tabular}{|c|c|c|c|c|}
\hline \multicolumn{5}{|c|}{$\begin{array}{c}\text { CUADRO } 5 \\
\text { CAMPEONES DEL CASO } 4\end{array}$} \\
\hline País & 1 & 2 & 3 & 4 \\
\hline 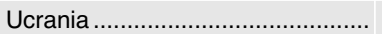 & 11 & 1 & 1 & 7 \\
\hline 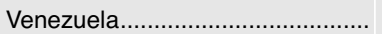 & 9 & 3 & 1 & 7 \\
\hline Grecia ......................................... & 9 & 4 & 2 & 5 \\
\hline 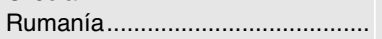 & 12 & 3 & 0 & 5 \\
\hline República Centroafricana.............. & 11 & 5 & 0 & 4 \\
\hline Eritrea & 6 & 10 & 0 & 4 \\
\hline 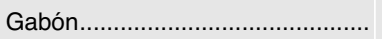 & 8 & 7 & 1 & 4 \\
\hline Jamaica & 8 & 6 & 2 & 4 \\
\hline Seychelles ............... & 13 & 2 & 1 & 4 \\
\hline 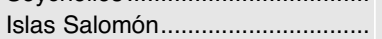 & 11 & 3 & 2 & 4 \\
\hline Togo & 11 & 4 & 1 & 4 \\
\hline
\end{tabular}

Se trata de países asolados por graves desastres: Ucrania se encuentra en guerra civil; Venezuela, en estado de devastación económica; la República Centroafricana, también destrozada por conflictos internos, es uno de los diez países más pobres del mundo. Y Grecia, ya sabemos.

España, con doce casos 1, cuatro casos 2, dos casos 3 y otros dos casos 4 , no aparece en ninguna de estas tablas de campeones porque en los cuatro rangos se encuentra muy abajo: en el puesto 86 en el caso 1, en el 78 en el 2 , en el 45 en el 3 y en el 37 en el 4.

Cabe plantearse varias preguntas interesantes.
- ¿Sube lo mismo el PIB cuando sube el gasto que cuando baja? ¿Más? ¿Menos?

- ¿A partir de qué aumento del gasto es seguro un incremento del PIB?

- Y viceversa: ¿a partir de que reducción del gasto es segura una disminución del PIB?

- Las disminuciones del gasto que van acompañadas de aumentos del PIB ¿son más pequeñas que las que van acompañadas de reducciones?

- ¿Hay un porcentaje óptimo de gasto público? Es decir, para un país determinado ¿se observa un porcentaje de gasto tal que, si se supera, el PIB disminuye?

- Si en un país el porcentaje de gasto público es mayor ¿es más probable que una variación del gasto vaya acompañada de una variación del PIB en el mismo sentido?

Para contestar a la primera pregunta se toman solamente los países donde, en el período analizado, ha habido al menos 5 aumentos de gasto y 5 disminuciones $^{2}$ (79 países de los 128). Por ejemplo, no se toma China, porque ha tenido 20 aumentos y ninguna disminución. Se halla entonces la media de las variaciones (aumentos y disminuciones) de PIB cuando aumenta el gasto y la media cuando disminuye. El resultado es claro: de media, el PIB aumenta casi el doble cuando crece el gasto público (4,52 por 100) que cuando dicho gasto disminuye $(2,47$ por 100$)$. Pero los comportamientos $\triangleright$

\begin{tabular}{|c|c|c|}
\hline \multicolumn{3}{|c|}{$\begin{array}{c}\text { CUADRO } 6 \\
\text { COMPORTAMIENTOS NACIONALES }\end{array}$} \\
\hline País & $\begin{array}{l}\text { Promedio } \Delta Y \\
\text { cuando } \Delta S>0\end{array}$ & $\begin{array}{l}\text { Promedio } \Delta \mathrm{Y} \\
\text { cuando } \Delta \mathrm{S}<0\end{array}$ \\
\hline España........................ & 2,73 & 0,79 \\
\hline Alemania ...................... & 0,99 & 2,04 \\
\hline EEUU ........................ & 2,54 & 1,96 \\
\hline Holanda...................... & 2,17 & 1,38 \\
\hline Italia ............................. & 0,20 & 0,80 \\
\hline Reino Unido ............... & 2,14 & 2,25 \\
\hline Portugal...................... & 1,71 & $-0,18$ \\
\hline Grecia ...................... & 2,87 & $-1,71$ \\
\hline
\end{tabular}

2 Esta regla de al menos 5 aumentos y al menos 5 disminuciones también se aplica para calcular las medias de variación de PIB con la variación de la deuda y con la variación de los ingresos del Estado. 
son muy diferentes según el país. Vemos algunos ejemplos en el Cuadro 6.

España sigue con creces la regla general (cuando aumenta el gasto público, el PIB español crece un 2,73 por 100 , y cuando este gasto baja, solo un 0,79 por 100$)$. También la siguen Estados Unidos y Holanda.

Pero en Alemania, Italia y Reino Unido sucede al revés: para el PIB es mejor bajar el gasto público que aumentarlo.

La explicación que cabe es que, previendo una disminución del PIB para el año siguiente, los Gobiernos intentan paliarla aumentando el gasto para ese año. También es posible que, ante una recesión que provoque un aumento sustancial del paro, crezca el gasto público por el mayor desembolso en subvenciones de desempleo.

De la misma manera hay que recordar que la reducción del gasto público puede no ser un acto voluntario del Gobierno, sino una consecuencia de la evolución económica. Por ejemplo, si aumentan los ingresos fiscales y se amortiza deuda, con lo que se paga menos por intereses. O si bajan los tipos de interés. O si se incrementa fuertemente el empleo y se reducen consecuentemente las subvenciones a los parados.

No debe pensarse en el incremento del gasto como una inyección en la economía de dinero «exterior» a ella. O bien se financia con aumentos de impuestos (con su posible efecto depresor del consumo) o bien (salvo los países que disponen de reservas soberanas provenientes de la explotación petrolífera) con deuda. El aumento de la deuda puede afectar al crecimiento por disminuir la confianza en el país, encarecer la financiación privada o absorber fondos que, en otra situación, irían a empresas (crowding out).

Portugal y Grecia muestran una clarísima sensibilidad al gasto público: cuando este se reduce, también lo hace su PIB $(-0,18$ y $-1,71$ por 100), mientras que cuando crece, el PIB responde en igual sentido $(1,71$ y 2,87 por 100 respectivamente).

Debe reseñarse que, en estos 79 países, el aumento promedio del gasto (12,41 por 100) es de magnitud superior al descenso promedio $(-7,44$ por 100$)$.

\section{Seguridad de aumentar el PIB}

Se trata ahora de contestar a la pregunta ¿cuánto es necesario subir el gasto público para asegurarse de que el PIB se incrementa?

Empíricamente, si consideramos no fiable (como ya se ha dicho) la variación (353 por 100) del gasto en Bielorrusia de 2000 a 2001, hay que triplicar el gasto público para asegurarse un aumento del PIB: el segundo mayor incremento en los 128 países analizados, un 194 por 100 en Guinea Ecuatorial entre 1997 y 1998, fue acompañado por un incremento del PIB del 23,77 por 100.

En esta lista de variaciones del gasto, ordenadas de mayor a menor, España no aparece hasta el puesto 858, para el período 20082009 , en que un incremento del gasto público del 7,2 por 100 fue acompañado de un descenso del PIB (- 3,6 por 100) en 2009.

\section{Reducir gasto sin bajar PIB}

En el apartado anterior queda parcialmente contestada la pregunta ¿a partir de que reducción del gasto es segura una disminución del PIB? Por desgracia, la disminución del PIB no solo es posible si se reduce el gasto, sino incluso si se aumenta. Depende del país, por supuesto. La reducción más drástica del gasto (-73,32 por 100) en Guinea Ecuatorial entre 1995 y 1996 fue acompañada de un aumento del PIB casi igual de drástico del 64,57 por 100 en 1996. La siguiente, $(-60,91$ por 100) en Libia en 2011 (por la guerra) vino asociada a una reducción del PIB del 62,08 por 100. 
Una visión de conjunto se muestra en el Gráfico 1: la inmensa mayoría de los puntos $\Delta Y-\Delta S$ se encuentra por encima de la línea horizontal que marca $\Delta Y=0$. Además, la nube de puntos no es circular (como lo sería en caso de dos fenómenos no relacionados), sino aplastada e inclinada. Puede trazarse una línea en la dirección de su tendencia.

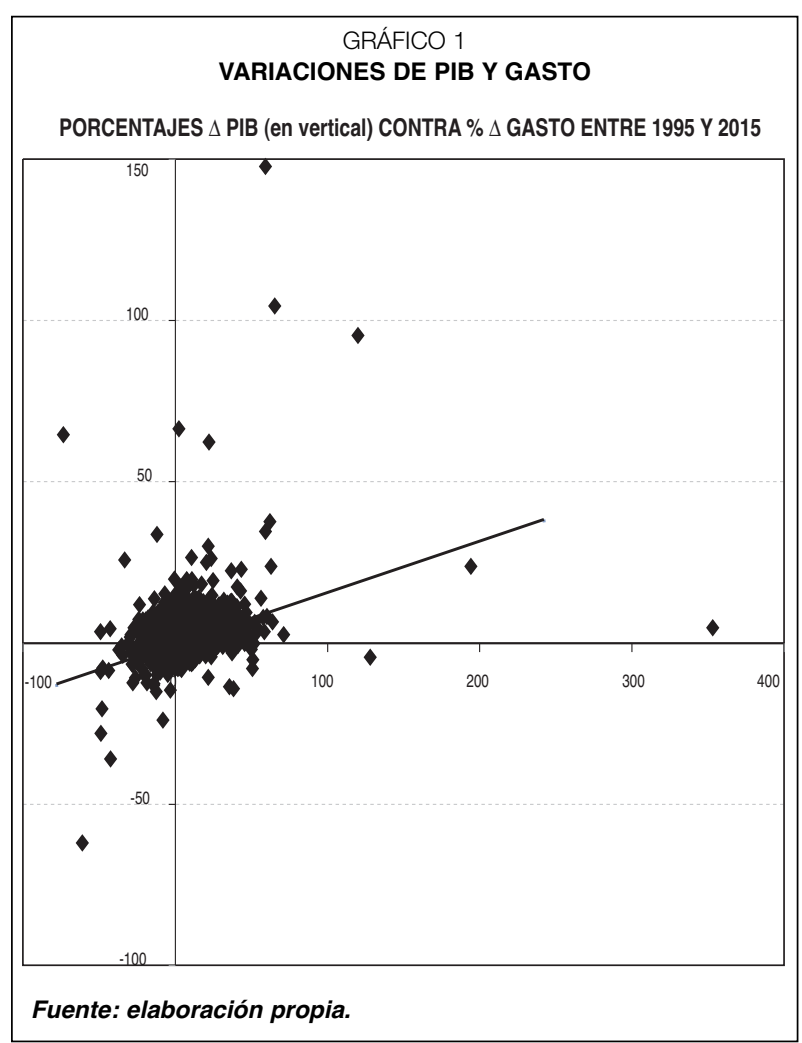

\section{Disminución del gasto que sube el PIB}

Se va a contestar ahora a la pregunta: las disminuciones del gasto que van acompañadas de aumentos del PIB ¿son más pequeñas que las que van acompañadas de reducciones? Para ello se toman, de los 128 países, aquellos donde al menos haya habido dos disminuciones del gasto acompañadas de aumentos del PIB y dos bajadas del gasto acompañadas de descensos del PIB. No son muchos, solo 33, España entre ellos.

La respuesta es afirmativa: para estos 33 países, la media de las reducciones del gasto que coinciden con un incremento del PIB es $-6,68$ por 100 , mientras que la media de las que coinciden con una disminución del PIB es casi el doble, $-12,92$ por 100 .

\section{Gasto público óptimo}

¿Existe un nivel de gasto público tal que, si se aumenta, el PIB empieza a descender, o crece claramente menos? De existir este efecto, donde más claramente se observaría sería en los campeones del caso 2 (Cuadro 3). Se van a examinar de cerca las evoluciones de Italia y Noruega, países cercanos, conocidos y no afectados por guerras ni desastres en el período.

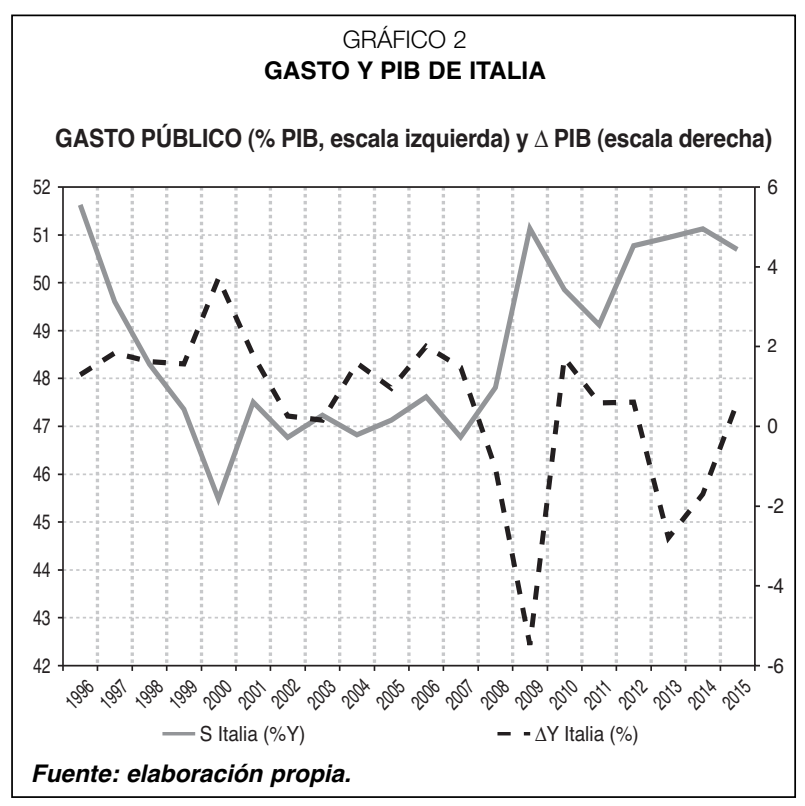

Puede verse que el punto de inflexión se produce en 2007: el PIB cae a plomo y sigue descendiendo hasta 2009. El gasto público sube, pero bastante menos de lo que aparenta en el gráfico (porque allí está representado en porcentaje del PIB, que desciende mucho). En realidad el gasto público de Italia en 2008 es solo un 1,15 por 100 superior al de 2007, y el de 2009 , solo un 1,09 por 100 mayor que el del año anterior. Vemos además que los niveles de gasto público se elevan (de 2001 a 2007 rondan el 47 por 100 del PIB, mientras que de $\triangleright$ 
2009 a 2015 rondan el 50 por 100), pero eso no impide que el incremento del PIB remonte en 2010 (ya con gasto público más alto) a los niveles de 2004-2007. Por tanto, cabe concluir que, si existe un nivel de gasto público óptimo para Italia, los datos manejados no permiten afirmar que lo haya alcanzado. Otra cosa es que, dado su elevado nivel de deuda, sea recomendable que lo incremente.

El caso de Noruega es distinto:

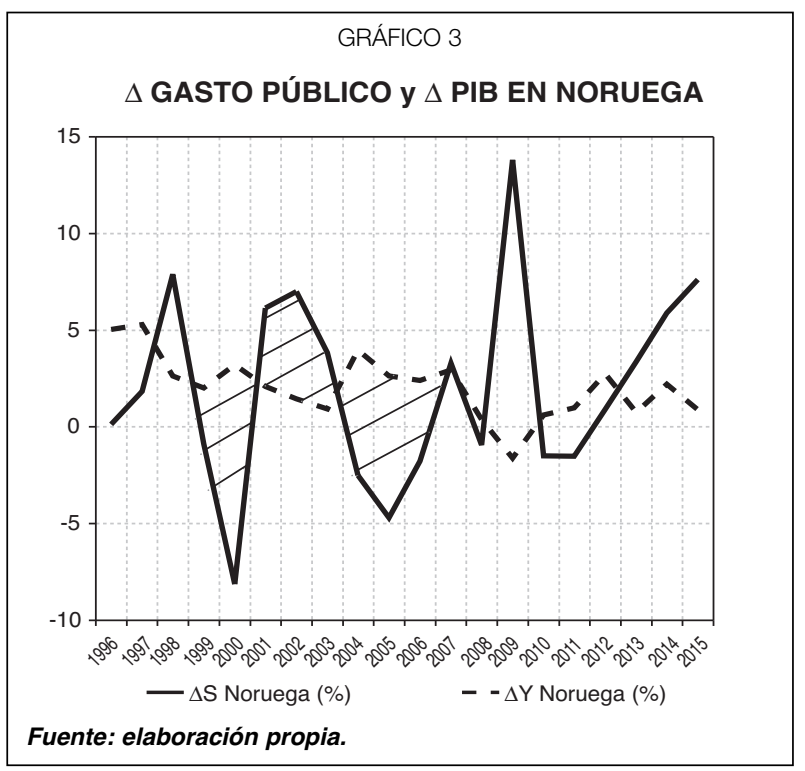

Si para Italia se ha representado con línea continua el gasto público como porcentaje del PIB en la escala izquierda, y la variación del PIB con línea de trazos en la escala derecha, para Noruega hay una sola escala, a la izquierda. Con línea continua se representan las variaciones del gasto público y con línea de trazos, las del PIB.

Se han rayado tres áreas. En la primera puede verse que, pese a una fuerte disminución del gasto, la variación positiva del PIB no se altera. En la segunda, lo contrario: que ante un fuerte incremento del gasto, el PIB crece menos. $Y$ en la tercera, lo mismo que en la primera: el gasto decrece con fuerza y el PIB sube más que en la anterior etapa. En 2009 se produce un enérgico incremento del gasto, seguramente para contrarrestar los efectos de la crisis.
A partir de 2012 el crecimiento del PIB ya es menor. De esto cabría concluir que Noruega tendría un nivel de gasto público óptimo en torno al 42 por 100 de su PIB.

\section{Tamaño relativo del gasto y efectos de su variación}

Se va a contestar a la última pregunta de las planteadas: si en un país el porcentaje de gasto público es mayor ¿es más probable que una variación del gasto vaya acompañada de una variación del PIB en el mismo sentido?

Para ello se dividirán los países en tres tramos según los porcentajes medios de gasto público respecto a PIB en el período analizado. El máximo corresponde a Kiribati $(88,66$ por 100 del PIB), pero se considera un dato anómalo y se toma Dinamarca $(54,41$ por 100$)$. El mínimo a Bangladés (12,55 por 100). Esto divide a los 128 países en 27 con gasto público alto, 57 con medio y 44 con bajo.

Pues bien, la probabilidad, en los países de gasto alto, de que una variación del gasto vaya acompañada de una variación del PIB de igual signo es de 0,71 , mientras que en los países de gasto bajo es de 0,74. Es decir, los países de gasto bajo parecen más sensibles a las variaciones de este que los de alto.

\section{9. $\Delta S$ como predictor $\Delta Y$}

Se van a comparar los promedios de los errores absolutos en una predicción de la variación del PIB basada solamente en la variación del gasto público.

Para ello se toman los campeones de los casos 1 a 4, más España y, para cada año del período 2006-2015, se intenta predecir la variación del PIB basándose en la variación del gasto público (por ejemplo, para predecir la variación del PIB de 2006 se tomaría la variación del gasto entre 2005 y 2006). 
Para hacer la predicción se buscan en los $n$ años anteriores ( $n$ varía de 5 a 10, porque otro factor que se quiere averiguar es: dada la constante evolución de la economía ¿cuál es el número óptimo de años pasados que debemos mirar para elaborar la mejor previsión del futuro?) las dos variaciones del gasto más parecidas que fueran acompañadas de una variación del PIB en el mismo sentido. Se obtiene la media y se calcula la previsión por regla de tres. Este algoritmo se ejecuta, tanto individualmente para cada país como para el grupo al que pertenece (con el fin de contestar a otra cuestión: el mejor predictor de una determinada economía ¿es ella misma o un conjunto de economías similares $?^{3}$ ).

En los casos de China y Bangladés este algoritmo prevé, para el número óptimo de años (9 y 10, respectivamente), una parte muy sustancial $(79,53$ y 69,93 por 100) de la variación promedio del PIB entre 2006 y 2015. Para otros países los errores son mayores (error medio de 3,59 puntos de PIB para España ${ }^{4}$ con el número óptimo de años, 10). Para los 44 países analizados el número de años óptimo, que minimiza el error de predicción, es 10 en trece casos ${ }^{5}$; 7 en diez casos, y 5 en ocho casos. Tres quintos de las veces la predicción, utilizando los datos solo del país en cuestión, es mejor que si se utilizan todos los datos de los países del grupo al que pertenece.

\section{0. $\Delta$ PIB y $\Delta$ deuda}

La evolución comparativa de las variaciones del gasto y del PIB se ha trasladado ahora a las de deuda y PIB. Para este análisis hay

\footnotetext{
3 Lo que, a su vez, suscita otra pregunta: ¿cuándo es una economía similar a otra? Pero eso es otra historia...

${ }^{4}$ Para comparar, una regresión lineal utilizando datos de los 20 años arroja un error medio de 2,04 puntos de PIB.

5 Como este análisis se ha hecho buscando, hasta en los 10 años pasados, las variaciones más parecidas, se ha hecho otro análisis buscándolas en los 15 años pasados, para determinar si el óptimo de los 10 años era solo aparente, por acumulación en el límite. El otro análisis confirma que no es aparente.
}

datos de menos países ${ }^{6}$, solamente 81 . El período analizado es el mismo, 1995-2015. Para las 1.620 (= 20 años * 81 países) variaciones conjuntas analizadas, se halla que lo más frecuente es que un aumento de la deuda vaya acompañado de un incremento del PIB: ocurre en 918 ocasiones. Lo segundo más habitual (507 ocasiones) es que una reducción de la deuda vaya acompañada de un crecimiento del PIB. Ahora bien, en promedio, el PIB se incrementa más $(4,73$ por 100$)$ si la deuda se reduce que si aumenta $(3,79$ por 100$)$.

\section{1. $\Delta$ pib y $\Delta$ ingresos del Estado}

Por último se traslada el análisis a las variaciones de ingresos del Estado y PIB.

Los ingresos del Estado no siempre provienen de impuestos: los países exportadores de petróleo suelen tener empresas petroleras nacionales que nutren buena parte de los ingresos del Tesoro. El ejemplo paradigmático es Arabia Saudí, un país donde prácticamente no hay impuestos. Lógicamente, estos países están siendo los más afectados por el período de bajos precios del oro negro que atraviesa actualmente el mundo.

En los otros países, cabría suponer que, si se incrementan los ingresos del Estado, podría reducirse el PIB, ya que los habitantes dispondrán de menos renta para consumir.

La realidad empírica es la contraria. De ingresos y PIB en el período analizado (19952015) hay datos de 123 países ${ }^{7}$. Pues bien, tomándolos conjuntamente, la variación media del PIB cuando aumentan los ingresos del Estado es 4,63 por 100, mientras que cuando se reducen es 1,37 por 100 . Si no tenemos en cuenta a los países productores de petróleo, $\triangleright$

\footnotetext{
6 Aplicando la regla de al menos 5 aumentos y al menos 5 disminuciones, las variaciones medias se calculan para solo 57 países.

7 Aplicando la regla de al menos 5 aumentos y al menos 5 disminuciones, las variaciones medias se calculan para solo 76 países.
} 
el efecto se modera, pero persiste: el PIB aumenta 4,38 por 100 cuando los ingresos crecen y solamente 2,04 por 100 cuando disminuyen.

\section{Conclusiones}

En los 128 países analizados y en el período 1995-2015, de media, el PIB aumenta casi el doble cuando crece el gasto público (4,52 por 100) que cuando dicho gasto disminuye (2,47 por 100$)$.

Un aumento de gasto público no conducirá siempre a un incremento del PIB, ni recortar el gasto llevará necesariamente a que el PIB caiga. Depende del tamaño de la variación que se decida y del país en cuestión. El comportamiento de unos países es muy diferente al de otros.

En promedio el PIB se incrementa más $(4,73$ por 100$)$ si la deuda se reduce que si aumenta (3,79 por 100$)$.

Resumiendo mucho, en general, para incrementar el PIB se debe aumentar el gasto público a la vez que se acrecientan los ingresos y a la vez que se reduce la deuda. En cada caso particular, cada país ya verá, examinando sus datos de los diez años anteriores, si su comportamiento sigue estas pautas o son más adecuadas otras medidas.

Conviene investigar a fondo, con datos más detallados si, en países comparables, el que variaciones comparables del gasto público conduzcan en unos casos a aumentos del PIB y en otros a disminuciones, se debe a que las partidas del gasto modificadas son diferentes. ¿Afecta lo mismo recortar en sanidad que en obras públicas? ¿En educación que en pensiones? Una evaluación de los posibles efectos pasados de la variación en cada partida podría ser de gran utilidad a los que tienen que tomar decisiones a futuro sobre dichas variaciones.

Es fundamental que los datos económicos puestos a disposición del público por parte de organismos internacionales sean tan accesibles, completos y consistentes como sea posible. Los buenos datos permiten fundamentar buenas decisiones, fomentar que se tomen razonadamente y reducir la incertidumbre.

\section{Bibliografía}

[1] BRADFORD DELONG, J. (2015). «Pequeños "booms" que causan grandes crisis". Madrid: El País. Disponible en:

$\mathrm{http}: / /$ economia.elpais.com/economia/ 2015/07/02/actualidad/1435849801_434471. html

[2] FMI (2015). World Economic Outlook Database. Washington. Disponible en:

https://www.imf.org/external/pubs/ft/weo/2015/ 02/weodata/index.aspx

[3] GOBIERNO DE LOS ESTADOS UNIDOS (2016). Ministerio de Comercio. Departamento de Análisis Económico. Datos nacionales. Disponible en:

http://www.bea.gov/iTable/iTable.cfm?reqid= 16\#reqid $=16 \&$ step $=1$ \&isuri $=1$

[4] KRUGMAN, P. (2015). «Demand, Supply, and Macroeconomic Models». Nueva York: The New York Times. Disponible en:

http://krugman.blogs.nytimes.com/2015/11/28/ demand-supply-and-macroeconomic-models/?partner=rss\&emc=rss\&_r=0/

[5] LACALLE, D. (2016) «La OCDE y el dudoso multiplicador del gasto público». Madrid: El Confidencial. Disponible en:

http://blogs.elconfidencial.com/mercados/ Ileno-de-energia/2016-02-23/la-ocde-y-el-du doso-multiplicador-del-gasto-publico_ 1156804/

[6] MANKIW, N.G. (1997). Macroeconomía (3 ${ }^{\mathrm{a}}$ edición). Barcelona: Antoni Bosch editor. 